\title{
Pasif Ev Sertifika Sisteminin Mevcut Binalarda Uygulanması: EnerPHit
} Sertifika Sistemi

\author{
Ahunur AŞIKOĞLU1, Müjde ALTIN², Necla Seval BAYRAM ${ }^{3}$ \\ ${ }^{1}$ Dokuz Eylül Üniversitesi, Mimarlık Fakültesi, Mimarlık Bölümü, İmir. \\ ${ }^{2}$ Dokuz Eylül Üniversitesi, Mimarlık Fakültesi, Mimarlık Bölümü, İmir. \\ ${ }^{3}$ Munzur Üniversitesi, Mühendislik Fakültesi, Inşaat Mühendisliği Bölümü, Tunceli.

$\begin{array}{rll}\text { Sorumlu yazare-posta: } & \text { ahunur.asikoglu@deu.edu.tr } & \text { ORCIDID:https://orcid.org/0000-0002-7227-1788 } \\ & \text { mujde.altin@deu.edu.tr } & \text { ORCIDID:https://orcid.org/0000-0001-6948-9463 } \\ & \text { nsevalerdem@gmail.com } & \text { ORCIDID:https://orcid.org/0000-0002-9522-0270 }\end{array}$

Geliş Tarihi: 03.08.2021 Kabul Tarihi: 07.10.2021

Öz

Günümüz koşullarını iyileştirmek ve gelecek nesillerin sağııkı bir dünyada yaşamasını sağlamak amacıyla, dünyada farklı alanlarda farklı çözüm arayışlarına başlanmış ve bu doğrultuda önemli adımlar atılmıştır. Yapı sektörü, enerji tüketimi açısından önde gelen sektörlerden biri olduğu için, binalarda enerji kullanımını azaltılırken, konforlu ve sağlıklı mekânlarda yaşam koşullarının oluşturulmasına yönelik adımlar çeşitli yönetmelik, direktif vb. çalışmalarla atılmaya başlanmıştır. 2010 yılında Avrupa Birliği tarafından yayınlanan Binalarda Enerji Performansı Direktifi revizyonuna göre, üye devletlerden

Anahtar kelimeler Yalıtım malzemesi; Pasif Ev; EnerPHit; Enerji tüketimi kendi NZEB (neredeyse sıfır enerjili bina) hedeflerini belirlemeleri ve uygulamaya koymaları istenmiştir. $\mathrm{Bu}$ süreçte, mevcut sertifika sistemlerinden, kriterleri ülkenin NZEB hedeflerine uygun olanların kullanımında bir artış meydana gelmiştir. Son yıllarda, farklı iklim bölgelerinde bulunan ülkeler tarafından Pasif Ev sertifika sistemi ve mevcut binalarda kullanılan versiyonu olan EnerPHit sertifika sistemi kriterlerine uygun yapılar inşa edilmeye başlanmıştır. Çalışmada; biri Türkiye'de olmak üzere, dünyadaki 34 farklı EnerPHit sertifikalı yapı teknik özellikleri ve ulaşılan sonuç değerler üzerinden detaylı olarak analiz edilmiştir. Bu çalışma ile literatüre EnerPHit sertifika sisteminin kriterlerinin, uygulama tekniklerinin incelenmesi ve analizi ile katkıda bulunulması, Türkiye için potansiyelinin aktarılması amaçlanmıştır. Türkiye'de mevcut yapı stokunun enerji etkin iyileştirilmesi ile ülkenin enerjide dışa bağımlıı̆̆ının büyük ölçüde azaltılması, sağlıklı ve konforlu binalar yaratılması ve enerji tüketim maliyetlerinin büyük oranda azaltılması sağlanmış olacaktır.

\section{Application Of The Passive House Certification System In Existing Buildings: EnerPHit Certification System}

\begin{abstract}
In order to improve today's conditions and to ensure a healthy life for future generations, different solutions have been sought in different areas around the world and important steps have been taken in this direction. As the building sector is one of the leading sectors in terms of energy consumption, steps towards creating living conditions in comfortable and healthy spaces made by various regulations, directives, etc. started to be taken with studies, while reducing the energy use in buildings. According to the Energy Performance in Buildings Directive-recast published by the European Union in 2010, member states were asked to set and implement their own NZEB (nearly zero energy building) targets. During this period, there has been an increase in the use of existing certification systems whose criteria meet the country's NZEB objectives. In recent years, countries in different climatic zones have started to construct buildings that comply with the Passive House certification system and the EnerPHit certification system, the version used in existing buildings. In the study, specifications have been analyzed in detail and the results achieved over values through 34 different EnerPhit certified buildings in the world, including one in Turkey. With this study, it is aimed to contribute to the literature with the examination the analysis of EnerPHit certification system criteria, the application techniques, potential for Turkey. Reducing the dependence on foreign energy in Turkey with energy efficient improvement of the existing building stock in country, creation of healthy and comfortable and energy consumption costs will be provided.
\end{abstract}

Keywords

Insulation material; Passive House;

EnerPHit; Energy consumption 


\section{Giriş}

Endüstri devrimi sonrasında, teknolojinin, üretimin, enerji talebi ve tüketiminin hızla artışı enerjiye bağımlılığı da büyük oranda arttırmıştır. "Dünyada teknolojinin gelişmesi ile birlikte enerjiye olan ihtiyaç çoğalırken, diğer taraftan ortaya çıkan nüfus artışı, enerjiye olan ihtiyacı daha da arttırmıştır. Kaynakları etkin ve verimli bir şekilde kullanmak, gelecek nesillere yaşanabilir bir dünya miras bırakabilmek için gereklidir." (Aşıkoğlu 2014)

Dünyada kaynaklar yenilenebilir ve yenilenemeyen kaynaklar (fosil kaynaklar) olarak iki grupta incelenebilir (Yeang 2008). Fosil yakıt tüketiminin azaltılması, enerji fiyatlarındaki artışlar, küresel ısınmaya bağlı çevresel sorunlar, enerjinin sanayi ve ulaşım sektörleri gibi yapılarda verimli kullanılmasını zorunlu kılmaktadır. (Yıldız vd. 2011) Petrol krizi, küresel ısınma, fosil kaynakların tükenmesi gibi pek çok çevresel sorun enerjiyi etkin kullanan yapı tasarımı doğrultusunda çözümlerin geliştirilmesine yönelik arayışlara ve çalışmalara neden olmuştur. Bu süreçte; çevreyle uyumlu, sürdürülebilir, enerjiyi etkin ve verimli kullanan, çevreye verilen zararı minimize eden yapı kabuğu tasarımına dair sistemler ortaya çıkmıştır. (Şenyurt ve Altın 2020).

Son 18 yılda Türkiye' de toplam enerji tüketiminin \%284, başka bir deyişle 3 kata yakın arttığı görülmektedir (Yearbook Enerdata 2020). Çevre ve Şehircilik Bakanlığı'na göre; Türkiye'de 2017 yılında toplam enerji tüketimi 145,3 Mtep (milyon ton eşdeğer petrol) olmuştur. 2017 yılında Türkiye'deki toplam enerji tüketiminin sektörlere göre dağılımına bakıldığında ise; en yüksek tüketimin \%24,8 ile mesken ve hizmetlerde olduğu görülmektedir. Mesken ve hizmetleri takiben; \%24,4 ile sanayi sektörü, \%23,1 ile enerji ve çevrim sektörü, \%19,6 ile ulaştırma, \%5,1 ile enerji dışı ve \%2,9 ile sektörlere göre enerji tüketimi oranlar dağılımda yer almaktadır (Çevre ve Şehircilik Bakanlığı 2020).

2 Ocak 2018 tarihli, 30289 sayılı Resmi Gazete'de yayınlanan Ulusal Enerji Verimliliği Eylem Planı 2017-2023'te; Türkiye İstatistik Kurumu (TÜiK) verilerine göre Türkiye'de 2017 yılı itibariyle 9,1 milyon adet bina bulunduğu ve bu binaların yaklaşık \%87'sini konutların oluşturduğu belirtilmektedir. Yapı kullanma izni istatistiklerine göre Türkiye'nin bina stokuna her yıl 100.000'den fazla yeni bina eklenmektedir (Ulusal Enerji Verimliliği Eylem Planı 2017).

Belirtilen istatistiklerden yola çıkarak; Türkiye'de yapı stoku açısından hızlı bir büyüme olduğu söylenebilmektedir. Enerji tüketiminde ülke çapında en büyük yüzdelik dilimi kapsayan binalar, en büyük enerji tasarrufunu yaratma potansiyeline sahiptir. Bu kapsamda; yeni yapılacak binaların daha verimli olması, mevcut binaların da enerji etkin iyileştirmelerinin yapılması, enerji tasarrufuna büyük katkı oluşturacaktır. Türkiye'de 2000 ve sonrasında inşa edilmiş yapılar, benzer derece-gün sayısına sahip Avrupa ülkelerindeki benzer yapılar ile karşılaştırıldığında, yapılarda ısıtma için \%50'den fazla enerjiye ihtiyaç duyduğu görülmüştür. Örneğin; izin verilen maksimum ısıtma tüketim değeri Danimarka'da 23kWh/m², Hollanda'da 34 $\mathrm{kWh} / \mathrm{m}^{2}$, Ingiltere'de ise $35 \mathrm{kWh} / \mathrm{m}^{2}$ iken, Türkiye'de ortalama ısıtma enerjisi ihtiyacı 110kWh/m²'dir. Türkiye'de, binalarda enerji tasarrufu potansiyelinin \%20-\%50 arasında olduğu belirtilmektedir (OEEB 2013).

2010 yılında yayınlanan Binalarda Enerji Performansı Direktifi (EPBD) revizyonuna göre, doğal gaz, katı yakıt gibi tükenebilir temel yakıt kaynaklarının; etkin, rasyonel ve sürdürülebilir kullanılması aynı zamanda karbondioksit emisyonunun yönetimini de önemli kılmaktadır. Avrupa Birliği Enerji Komisyonu tarafından yayınlanan Binalarda Enerji Performansı Direktifi 'ne göre; 31 Aralık 2018'e kadar tüm kamu binaları, 31 Aralık 2020 tarihine kadar da tüm yeni binalar, NZEB (Neredeyse Sıfır Enerjili Bina) koşullarına uygun olmalıdır (European Union [EU] 2010). Üye devletler, NZEB sayısını arttırabilmek için bina kategorilerine göre farklılaşmış hedefleri içeren ulusal planlar düzenlemektedirler. Bu doğrultuda, başta Avrupa'da olmak üzere tüm dünyada 
binalarda enerjiyi etkin ve verimli kullanacak çözümler geliştirilmeye başlanmıştır (ECOFYS 2014).

Türkiye'de ve Avrupa'da bina sektöründeki enerji tüketiminin azaltılmasına yönelik çalışmalar sürdürülmektedir. Yapıların sürdürülebilirliği açısından, tasarım aşamasında verilen kararlar büyük önem taşımaktadır. Yapı kabuğunun uygun tasarımıyla, yapıların ömrü uzatılabilirken, kullanıcıların konforlu bir ortamda yaşamaları sağlanıp, enerji tüketimini azaltmak mümkün olmaktadır (Umaroğulları vd. 2011).

Bir yapının bulunduğu iklim kuşağının karakteristik özellikleri; yapının ısıtılması, soğutulması, aydınlatılması ve havalandırılmasına büyük ölçüde etki etmektedir. Yapı içindeki konfor koşulları sağlanırken; aktif ısıtma, soğutma, havalandırma ve aydınlatma sistemlerine olan ihtiyacı en aza indirecek pasif sistem çözümleri geliştirilmiştir (Aşıkoğlu ve Altın 2016).

Günümüzde enerji etkin binalar üretmek için aktif ve pasif sistem çözümleri kullanılmaktadır. Bu çalışma; binalarda enerjiyi etkin kullanmak üzere pasif teknikler kullanılarak geliştirilmiş bir sertifika sistemi olan Pasif Ev standartlarının mevcut binalarda kullanımını içeren EnerPHit sertifika sisteminin kriterlerini ve farklı iklim bölgelerindeki uygulama örneklerini kapsamaktadır. Bu çalışmada; EnerPHit sertifika sisteminin uygulanma yöntemleri, yapı bileşenlerinde yalıtım için kullanılan malzeme tipleri ve kullanım sıklıkları, yapılan iyileştirmelerde yapı bileşenlerine göre yalıtım kalınlığı seçimleri, ulaşılan U-değerleri ve tüm müdahaleler sonucunda farklı bölgelerde elde edilen sonuç enerji tüketim değerlerini analiz etmek amacıyla; bu sertifikayı almış dünyanın çeşitli bölgelerinde bulunan yapılar ele alınıp incelenmiştir.

\section{Materyal ve Metot}

Dünyada yaygın kullanıma sahip Pasif Ev EnerPHit sertifikasına sahip binalar kullanılan malzeme, elde edilen yapı bileşeni U-değerleri (ısıl iletkenlik katsayısı) ve ulaşılan enerji intiyacı vb. parametreler açısından analiz edilmiştir. İzmir ili için kriterleri asgari düzeyde karşılayan bir uygulama, simülasyon programı aracılığı ile yapılmış ve elde edilebilecek enerji tasarrufu saptanıp değerlendirilmiştir.

\subsection{Pasif Ev ve EnerPHit Sertifika Sistemi}

Binaların tasarımı ve inşasında pasif yaklaşımlar; ilk çağlardan günümüze sıklıkla karşımıza çıkmaktadır. Yaşam alanlarındaki konfor koşullarının pasif havalandırma, aydınlatma, soğutma gibi teknikler kullanılarak iyileştirilmesi, hemen her mimari dönemde görülebilmektedir. Pasif standartlara uygun olarak yapılmış bir bina, rahat ve sağlıklı kullanım için tasarlanmış, farklı iklim bölgelerinde farklı çözümlerle, geleneksel yapım yöntemleri ile inşa edilmiş yapılara göre daha az enerji tüketen yapıdır" (Cotterel and Dadeby 2014). Pasif Ev; enerji verimli, konforlu ve düşük enerji kullanım maliyetli bir bina standardıdır. Pasif Ev'ler, geleneksel yöntemlerle inşa edilmiş bir binaya göre büyük oranda ısıtma ve soğutma ile ilgili enerji tasarrufu sağlamaktadır. Pasif Ev standartlarını belirlemek ve kontrol etmek amacıyla Wolfgang Feist tarafından 1996 yılında Darmstadt'da "Passivhaus Institut" (Pasif Ev Enstitüsü) kurulmuştur. (İnt Kyn. 1)

Farklı iklim bölgelerinde, 2013 yılından bu yana yaklaşık 50,000 Pasif Ev yapısı inşa edilmiş olduğu göz önünde bulundurularak, Pasif Ev sertifika sisteminin, dünyanın önde gelen binalarda enerji verimliliği sertifika sistemlerinden biri olduğu söylenebilmektedir. (Liang et al. 2017)

Pasif Ev standartları temel olarak karasal iklime sahip bölgelerde, ısıtma enerjisi ihtiyacının azaltılmasına yönelik oluşturulmuştur. Son yıllarda soğutma enerjisi tüketiminin büyük önem taşıdığı güney Avrupa ülkelerine yönelik çözümler de geliştirilmeye başlanmıştır.(Eerg 2, Causeone et al. 2017, Hopfe and McLeod 2015) Pasif Ev tasarımının temel prensiplerini; minimize edilmiş veya azaltılmış ıSı kayıpları, pasif güneş enerjisi kullanımı, havalandırma ve yaz için güneş kontrolü olarak sıralamak mümkündür. (Schnieders et al. 2020)

Pasif Ev standartları ile bir yıl boyunca bir metrekare yaşam alanını ısıtmak için 1.5 litreden az petrol, 1.5 
$\mathrm{m}^{3 \prime}$ ten az gaz, $15-20 \mathrm{kWh} / \mathrm{m}^{2 \prime}$ den az elektrik kullanımı hedeflenmektedir (İnt Kyn. 2)

Günümüzde; binaların aktif soğutmaya ihtiyaç duyduğu sıcak iklimlerde de Pasif Ev sistemi ile büyük enerji tasarrufu sağlanabilmektedir. Pasif Ev; güneşi, iç ısı kaynaklarını ve ısı geri kazanımını verimli bir şekilde kullanırken, en soğuk kış aylarında bile geleneksel ısıtma sistemlerini gereksiz kılabilmektedir. Sıcak aylarda ise, Pasif Ev, serinletme için stratejik gölgeleme gibi pasif soğutma tekniklerinden de yararlanmaktadır. (Int Kyn. 2)

Pasif Ev Enstitüsü'nün yeni binalar için belirlediği kriterler aşağıdaki gibi sıralanmaktadır;

- Isıtma enerjisi tüketimi yıllık metrekare başına 15 $\mathrm{kWh} / \mathrm{m}^{2 \prime}$ den düşük,

- Soğutma ve nemlendirme enerjisi tüketimi yıllık metrekare başına $15 \mathrm{kWh} / \mathrm{m}^{2 \prime}$ den düşük,

- Birincil enerji (sıcak su, evsel elektrik vb.) tüketimi yıllık metrekare başına $120 \mathrm{kWh} / \mathrm{m}^{2 \prime}$ den düşük,

- Hava geçirmezlik 50 Pa basınç altında saatlik 0,6'dan düşük olmalıdır. (İnt Kyn. 3)

Pasif Ev Enstitüsü’nün mevcut binalar için belirlediği kriterler EnerPHit sertifika sistemi olarak tanımlanmaktadır. (Passipedia 2018.)

\subsection{EnerPHit Kriterleri}

Pasif Ev Enstitüsü'ne göre, mevcut binalarda EnerPHit kriterlerini sağlayabilmek için kullanıcıya iki yöntem alternatifi sunulmaktadır. Bu yöntemler;

Yöntem 1: Yapı bileşeni U değeri yöntemi (Çizelge 1) Yöntem 2: Enerji talebi yöntemidir. (Çizelge 2)

EnerPHit sertifikası için bu yöntemlerden sadece birinin kriterlerinin karşılanması gerekmektedir. EnerPHit sertifika sisteminde belirtilen kriterler, yapının bulunduğu iklim bölgesine göre farklılıklar göstermektedir. İklim bölgelerine göre standart sınır değerler Çizelge 1 ve Çizelge 2'de belirtilmiştir.

Pasif Ev Enstitüsü; yapının içinde bulunduğu bölge için iklim sınıflandırmasını; PHPP (Passive House
Planning Packet) iklim verileri sistemi aracılığı ile kullanıcıya belirtmektedir.

Çizelge 1. Yöntem 1; yapı bileşeni U değeri yöntemi

\begin{tabular}{|c|c|c|c|}
\hline $\begin{array}{l}\text { PHPP'ye } \\
\text { göre iklim } \\
\text { bölgesi }\end{array}$ & $\begin{array}{l}\text { Pencere } \\
(U-\text { değeri } \\
\left.W /\left(\mathrm{m}^{2} \mathrm{~K}\right)\right) \text {, (g- } \\
\text { değeri })\end{array}$ & $\begin{array}{l}\text { Duvar/Çatı/Zemin } \\
\text { (U-değeri W/(m² } \mathrm{K}))\end{array}$ & $\begin{array}{l}\text { Minimum } \\
\text { Isı geri } \\
\text { kazanım } \\
\text { oranı }\end{array}$ \\
\hline Arktik & $0.45, U^{\mathrm{g}}-\mathrm{g} * 0.7 \leq 0$ & 0.09 & $80 \%$ \\
\hline Soğuk & $0.65, U^{\mathrm{g}}-\mathrm{g} * 1.0 \leq 0$ & 0.12 & $80 \%$ \\
\hline Soğuk-ılıman & $0.85, \mathrm{U}^{\mathrm{g}} \mathrm{-g} * 1.6 \leq 0$ & 0.15 & $75 \%$ \\
\hline Sıcak-ılıman & $1.05, U^{g}-g * 2.8 \leq-1$ & 0.3 & $75 \%$ \\
\hline Ilıman & $1.25,-$ & 0.5 & - \\
\hline Sicak & $1.25,-$ & 0.5 & - \\
\hline Çok sıcak & $1.05,-$ & 0.25 & - \\
\hline
\end{tabular}

Çizelge 2. Yöntem 2; Enerji talebi yöntemi (Passipedia 2018.)

\begin{tabular}{lll}
\hline $\begin{array}{l}\text { PHPP'ye göre } \\
\text { iklim bölgesi }\end{array}$ & $\left.\begin{array}{l}\text { Isıtma (Maksimum } \\
\text { [sıh/(tmalebi) }\end{array}\left(\mathrm{m}^{2} \mathrm{a}\right)\right]$ & $\begin{array}{l}\text { Soğutma (Maksimum } \\
\text { soğutma ve nemlenme } \\
\text { talebi) }\left[\mathrm{kwh} /\left(\mathrm{m}^{2} \mathrm{a}\right)\right]\end{array}$ \\
\hline $\begin{array}{l}\text { Arktik } \\
\text { Soğuk }\end{array}$ & 35 & \\
Soğuk-ılıman & 25 & \\
Sıcak-ılıman & 20 & $\begin{array}{c}\text { PassivHaus kriterlerinde } \\
\text { belirtilen değerlere eşittir }\end{array}$ \\
Ilıman & 15 & \\
Sıcak & - & \\
Çok sıcak & - & \\
\hline
\end{tabular}

Tasarımcı, yapının bulunduğu iklim bölgesi için, yapı bileşeni $U$ değerleri yönteminde (Çizelge 1) belirtilen, opak yapı kabuğu bileşenleri, pencereler, dış kapılar ve havalandırma için sınır değerleri ya da enerji talebi yönteminde (Çizelge 2) belirtilen, maksimum ısıtma ve soğutma talebi sınır değerlerinin koşullarını sağlayarak mevcut yapıyı EnerPHit sertifikasına uygun hale getirebilmektedir.

\subsection{EnerPHit Sertifikalı Binaların Analizi}

EnerPhit sertifikası kriterleri doğrultusunda; mevcut binalar üzerinde yapılan enerji enerji etkin iyileştirmelerinin incelenmesi ve değerlendirilmesi amacıyla çalışmanın devamında sertifikalanmış yapıların analizi yapılmıştır. EnerPHit sertifikasının uygulanma teknikleri, malzeme seçimleri, farklı iklim bölgelerindeki seçimlerin analiz edilmesi amacıyla bu bölümde sertifikalı örnekler incelenmiştir. Bu doğrultuda; 2017 yılına kadar EnerPHit sertifikası 
almış ve Pasif Ev veritabanında (Int Kyn. 4) yer almış farklı bölgelerde bulunan yapıların tamamı (34 yapı) bu çalışma kapsamında ele alınmıştır.

EnerPHit sertifikası almış 34 yapı; aşağıdaki parametreler açısından incelenmiştir;

-Yapım yeri,

-Kullanım tipi,

-Duvar yalıtım malzemesi, duvar U-değeri,

-Zemin yalıtım malzemesi, zemin U-değeri,

-Çatı yalıtım malzemesi, çatı U-değeri,

-Pencereler, pencere U-değeri,

-Yıllık metrekare başına ısıtma enerjisi ihtiyacı $\left(k W h /\left(m^{2} a\right)\right)$,

-Yıllık metrekare başına birincil enerji ihtiyacı $\left(k W h /\left(m^{2} a\right)\right)$.

Incelenen 34 yapıdan $10^{\prime} \mathrm{u} \quad \mathrm{ABD}^{\prime} \mathrm{de}$, altısı Almanya'da, beşi İngiltere'de, üçü Fransa'da, ikişer tanesi Avusturya, İrlanda, İspanya ve Japonya'da, birer tanesi de Türkiye ve Avustralya'da bulunmaktadır. İncelenen yapılarda duvar, çatı ve zeminde enerji etkin iyileştirme yapılırken, kullanılan malzemeler ve kullanım sıklığı incelendiğinde pek çok yalıtım malzemesinin kullanıldığı görülmüştür (Şekil 1).

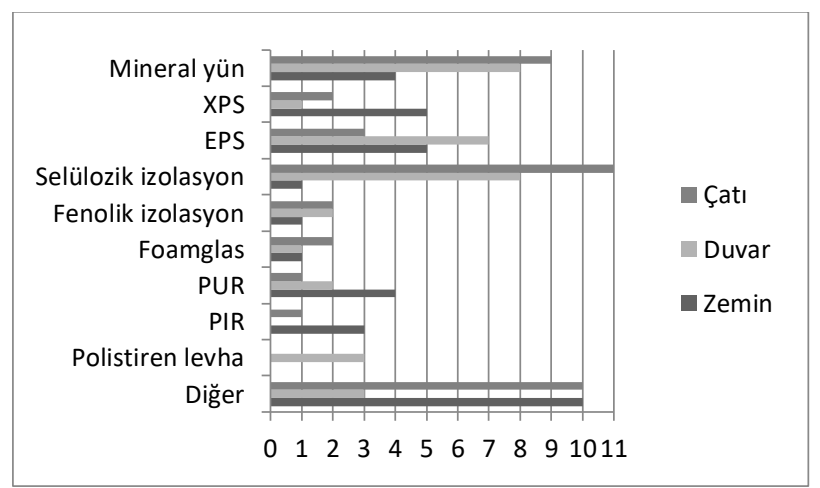

Şekil 1. Çatı, duvarve zeminde kullanılan yalııım Malzemesi cinsi ve kullanım sıklığı

Çatı yalıtım malzemesi olarak en yüksek sıklıkta sırasıyla; selülozik izolasyon, mineral yün ve EPS, duvar yalıtım malzemesi olarak en yüksek sıklıkta sırasıyla; selülozik izolasyon, mineral yün, EPS, PUR ve XPS, zemin yalıtım malzemesi olarak en yüksek sıklıkta sırasıyla; XPS, EPS, mineral yün kullanıldığı saptanmıştır. İncelenen yapıların bir kısmında kullanılan yalıtım malzemesi belirtilmemiştir. Bu yapılar için malzeme seçimleri diğer olarak belirtilmiştir.

Çizelge 3. İncelenen örneklerde ülkelere göre duvar U-değerleri $\mathrm{W} /\left(\mathrm{m}^{2} \mathrm{~K}\right)$

\begin{tabular}{|c|c|c|c|c|c|c|c|c|c|c|}
\hline & \multicolumn{10}{|c|}{ Ülkelere göre duvar U-değerleri $\left(\mathrm{W} /\left(\mathrm{m}^{2} \mathrm{~K}\right)\right)$} \\
\hline & 1 & 2 & 3 & 4 & 5 & 6 & 7 & 8 & 9 & 10 \\
\hline ABD & 0.106 & 0.158 & 0.14 & 0.332 & 0.268 & 0.219 & 0.259 & 0.226 & 0.26 & 0.296 \\
\hline Almanya & 0.11 & 0.106 & 0.18 & 0.183 & 0.139 & 0.12 & & & & \\
\hline Avustralya & 0.223 & & & & & & & & & \\
\hline Avusturya & 0.089 & 0.12 & & & & & & & & \\
\hline Fransa & 0.189 & 0.121 & 0.119 & & & & & & & \\
\hline Ingiltere & 0.173 & 0.101 & 0.136 & 0.132 & 0.2 & & & & & \\
\hline irlanda & 0.13 & 0.17 & & & & & & & & \\
\hline İspanya & 0.264 & 0.132 & & & & & & & & \\
\hline Japonya & 0.077 & 0.201 & & & & & & & & \\
\hline Türkiye & 0.149 & & & & & & & & & \\
\hline
\end{tabular}

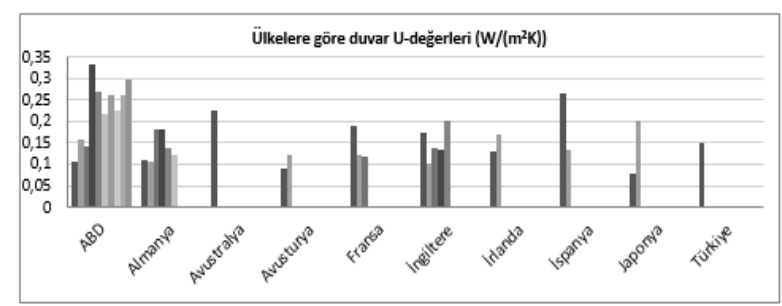

Şekil 2. İncelenen örneklerde ülkelere göre duvar U-değerleri grafiksel gösterimi $\mathrm{W} /\left(\mathrm{m}^{2} \mathrm{~K}\right)$

Çizelge 4. İncelenen örneklerde ülkelere göre zemin U-değerleri $\mathrm{W} /\left(\mathrm{m}^{2} \mathrm{~K}\right)$

\begin{tabular}{|c|c|c|c|c|c|c|c|c|c|c|}
\hline & \multicolumn{10}{|c|}{ Ülkelere göre zemin U-değerleri $\left(\mathrm{W} /\left(\mathrm{m}^{2} \mathrm{~K}\right)\right)$} \\
\hline & 1 & 2 & 3 & 4 & 5 & 6 & 7 & 8 & 9 & 10 \\
\hline ABD & 0.145 & 0.27 & 0.91 & 0.82 & 0.269 & 0.314 & 0.273 & 0.27 & 0.26 & 0.437 \\
\hline Almanya & 0.174 & 0.452 & 0.169 & 0.16 & 0.14 & & & & & \\
\hline Avustralya & 0.284 & & & & & & & & & \\
\hline Avusturya & 0.128 & 0.189 & & & & & & & & \\
\hline Fransa & 0.538 & 0.108 & & & & & & & & \\
\hline Ingiltere & 0.122 & 0.105 & 0.097 & 0.108 & 0.18 & & & & & \\
\hline irlanda & 0.1 & 0.131 & & & & & & & & \\
\hline İspanya & 0.222 & 0.143 & & & & & & & & \\
\hline Japonya & 0.178 & 0.276 & & & & & & & & \\
\hline Türkiye & 0.169 & & & & & & & & & \\
\hline
\end{tabular}

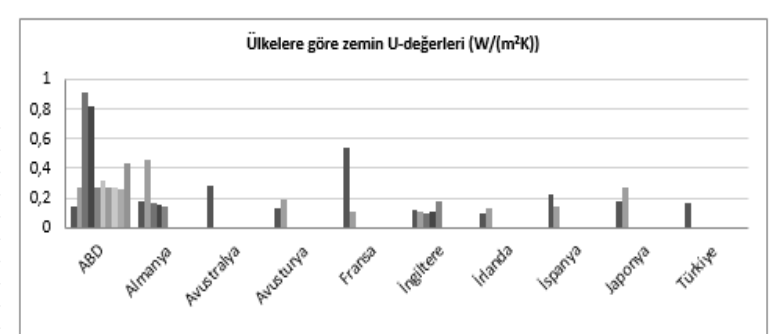

Şekil 3. İncelenen örneklerde ülkelere göre zemin Udeğerleri grafiksel gösterimi $\mathrm{W} /\left(\mathrm{m}^{2} \mathrm{~K}\right)$

Çizelge 5. İncelenen örneklerde ülkelere göre çatı U-değerleri $\mathrm{W} /\left(\mathrm{m}^{2} \mathrm{~K}\right)$

\begin{tabular}{|c|c|c|c|c|c|c|c|c|c|c|}
\hline & \multicolumn{10}{|c|}{ Ülkelere göre çatı U-değerleri (W/(m² $\mathrm{K}))$} \\
\hline & 1 & 2 & 3 & 4 & 5 & 6 & 7 & 8 & 9 & 10 \\
\hline ABD & 0.11 & 0.112 & 0.086 & 0.083 & 0.13 & 0.12 & 0.116 & 0.113 & 0.114 & 0.145 \\
\hline Almanya & 0.174 & 0.088 & 0.117 & 0.148 & 0.1 & & & & & \\
\hline Avustralya & 0.172 & & & & & & & & & \\
\hline Avusturya & 0.141 & & & & & & & & & \\
\hline Fransa & 0.108 & 0.092 & 0.086 & & & & & & & \\
\hline Ingiltere & 0.14 & 0.112 & 0.112 & 0.1 & 0.13 & & & & & \\
\hline írlanda & 0.11 & 0.115 & & & & & & & & \\
\hline İspanya & 0.133 & 0.149 & & & & & & & & \\
\hline Japonya & 0.063 & 0.145 & & & & & & & & \\
\hline Türkiye & 0.201 & & & & & & & & & \\
\hline
\end{tabular}




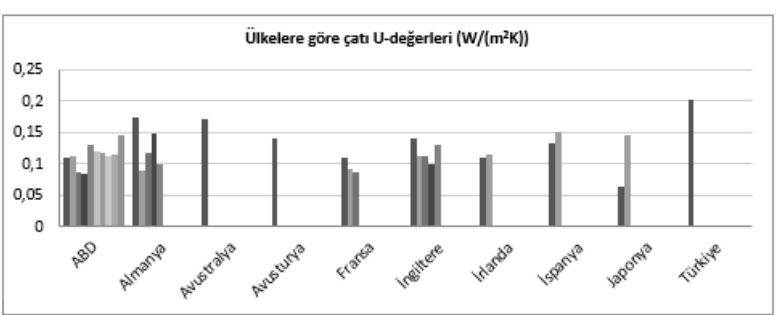

Şekil 4. İncelenen örneklerde ülkelere göre çatı Udeğerleri grafiksel gösterimi $\mathrm{W} /\left(\mathrm{m}^{2} \mathrm{~K}\right)$

Çizelge 1 ve 2'de gösterilen seçenekli EnerPHit kriterleri (yapı bileşenleri U-değerleri kriterleri ve enerji talebi yöntemi), yapının bulunduğu iklim bölgesine göre seçimler yapılması gerektiğini belirtmektedir. Her ülkenin bulunduğu iklim koşulları ve bu koşullara mekânların enerji etkin ve konforlu adapte edilmesi amacı; ülkelerin malzeme tip seçimlerini, kalınlık seçimlerini, detay çözümlerini, farklı yapı bileşenlerinde ulaştıkları ısıl iletkenlik değerlerini farklılaştırmaktadır. Bu nedenle ülkelere ait duvar, zemin ve çatı $U$ değerleri, Şekil 2, Şekil 3, Şekil 4'de ve Çizelge 3, Çizelge 4, Çizelge 5’de verilmiştir.

Incelenen yapılarda, duvar, zemin ve çatıda ulaşılan U-değerleri; yapı bileşenine göre ve ülkelere göre farklılık göstermektedir. Ele alınan örneklerde, enerji etkin yenileme sonucunda duvarda ulaşılan en düşük U-değerinin 0,077 W/( $\left.\mathrm{m}^{2} \mathrm{~K}\right)$ ile Japonya' da, en yüksek $U$-değerinin ise $0,332 \mathrm{~W} /\left(\mathrm{m}^{2} \mathrm{~K}\right)$ ile $A B D^{\prime}$ de olduğu görülmektedir. Zeminde enerji etkin iyileştirme kapsamında yapılan yalıtıma bakıldığında ise; en düşük U-değerinin 0,097 W/( $\left.\mathrm{m}^{2} \mathrm{~K}\right)$ ile Ingiltere' de, en yüksek U-değerinin ise $0,91 \mathrm{~W} /\left(\mathrm{m}^{2} \mathrm{~K}\right)$ ile ABD'de olduğu görülmektedir. İncelenen örnekler kapsamında çatıda, yapılan iyileştirme sonucunda ulaşılan en düşük U-değerinin 0,063 $\mathrm{W} /\left(\mathrm{m}^{2} \mathrm{~K}\right)$ ile Japonya'da, en yüksek U-değerinin $0,201 \mathrm{~W} /\left(\mathrm{m}^{2} \mathrm{~K}\right)$ ile Türkiye'de olduğu görülebilmektedir.

İncelenen örneklerin tamamı göz önünde bulundurulduğunda; yalıtım kalınlığının en çok arttığı, dolayısıyla U-değerinin en az olduğu yapı bileşeninin çatı olduğu saptanmıştır. Bu açıdan bakıldığında, yapılan yalıtımın kalınlığı sırasıyla; zemin, duvar ve çatıda arttığı görülmektedir. Örneklerde genel olarak; yalıtımın en az düzeyde kullanıldığı yapı bileşeni olan zeminde; duvar ve çatıya kıyasla daha yüksek U-değerlerine ulaşıldığı saptanmıştır.

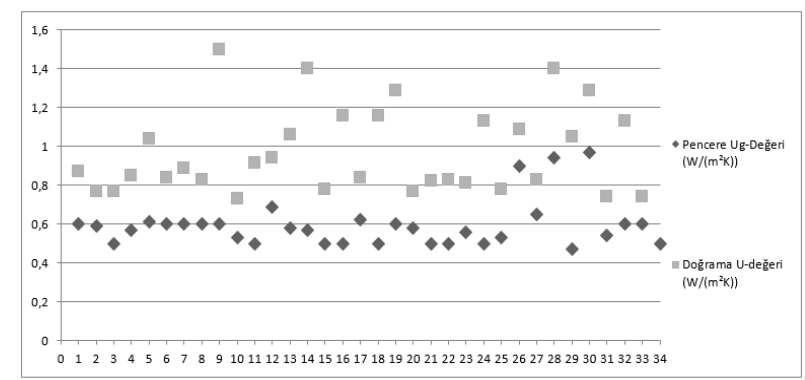

Şekil 5. İncelenen örneklerde pencere cam ve doğramalarına ait U-değerleri $\left(\mathrm{W} /\left(\mathrm{m}^{2} \mathrm{~K}\right)\right)$

Incelenen yapıların tamamı göz önüne alındığında; pencerelerde kullanılan cam Ug-değerinin büyük bir çoğunlukta $0,5 \mathrm{~W} /\left(\mathrm{m}^{2} \mathrm{~K}\right)$ ile $0,6 \mathrm{~W} /\left(\mathrm{m}^{2} \mathrm{~K}\right)$ arasında, yapıların sadece üçünde $0,8 \mathrm{~W} /\left(\mathrm{m}^{2} \mathrm{~K}\right)^{\prime}$ in üstünde olduğu saptanmıştır. Pencerelerin tamamının üçlü cam, birçoğunun Argon dolgulu seçildiği görülmektedir. Yüksek yalıtımlı, hava sızdırmaz, düşük U-değerli pencere seçimleri ile saydam yüzeylerde oluşan ısı kaybının önüne geçilebilmiştir.

Çizelge 6. Incelenen örneklerde yıllık $\mathrm{m}^{2}$ başına ısıtma enerjisi ihtiyacı $\left(\mathrm{kWh} / \mathrm{m}^{2} \mathrm{a}\right)$

\begin{tabular}{|c|c|c|c|c|c|c|c|c|c|c|}
\hline & \multicolumn{10}{|c|}{ Ülkelere göre ylllık $\mathrm{m}^{2}$ başıına Isıtma enerjisi ihtiyacı ( $\left.\mathrm{kWh} / \mathrm{m}^{2} \mathrm{a}\right)$} \\
\hline & 1 & 2 & 3 & 4 & 5 & 6 & 7 & 8 & 9 & 10 \\
\hline ABD & 27 & 22 & 25 & 15 & 22 & 25 & 20 & 16 & 19 & 20 \\
\hline Almanya & 17 & 39 & 24 & 30 & 15.7 & 26 & & & & \\
\hline Avustralya & 14 & & & & & & & & & \\
\hline Avusturya & 16 & 20 & & & & & & & & \\
\hline Fransa & 22 & 25 & 20 & & & & & & & \\
\hline Ingiltere & 23 & 23 & 18 & 33 & 52 & & & & & \\
\hline İrlanda & 17 & 21 & & & & & & & & \\
\hline İspanya & 49 & 20 & & & & & & & & \\
\hline Japonya & 21 & 19.5 & & & & & & & & \\
\hline Türkiye & 20 & & & & & & & & & \\
\hline
\end{tabular}

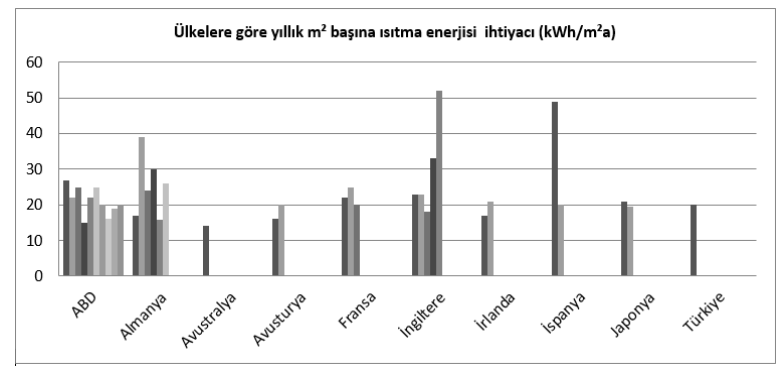

Şekil 6. İncelenen örneklerde yıllık $\mathrm{m}^{2}$ başına ısıtma enerjisi ihtiyacı grafiksel gösterimi ( $\left.\mathrm{kWh} / \mathrm{m}^{2} \mathrm{a}\right)$ 
Çizelge 7. Incelenen örneklerde yıllık $\mathrm{m}^{2}$ başına birincil enerji ihtiyacı $\left(\mathrm{kWh} / \mathrm{m}^{2} \mathrm{a}\right)$

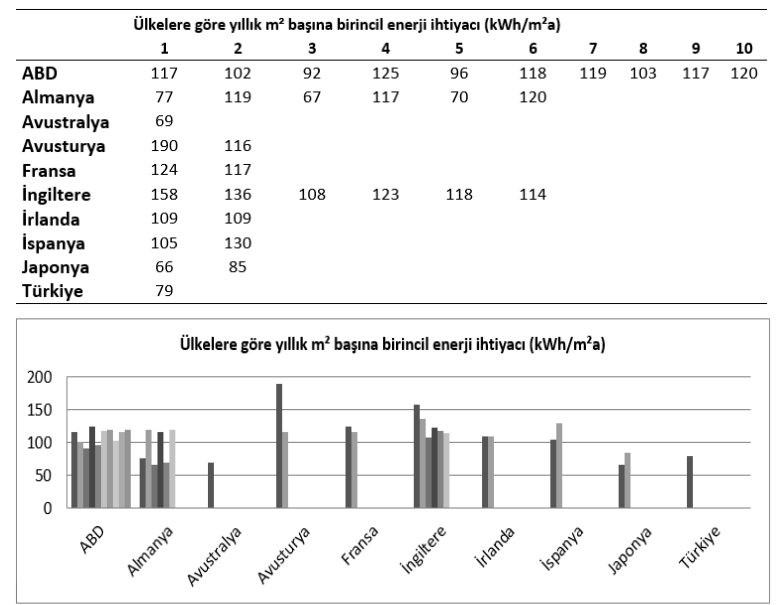

Şekil 7. Incelenen örneklerde yıllık $\mathrm{m}^{2}$ başına birincil enerji ihtiyacı grafiksel gösterimi $\left(\mathrm{kWh} / \mathrm{m}^{2} \mathrm{a}\right)$

Çatı, duvar, zemin, pencerelerde EnerPHit sertifikası kriterleri doğrultusunda yapılan enerji etkin iyileştirmelere dair çözümler incelendikten sonra, yapılan iyileştirmelerin enerji tüketimine etkisi ve ulaşılan tüketim değerleri Şekil 6, Şekil 7 ve Çizelge 6, Çizelge 7'de belirtilmiştir. Incelenen EnerPHit sertifikalı yapılarda, ülkelere göre metrekare başına yıllık ısıtma enerjisi ihtiyacı en düşük $14 \mathrm{kWh} /\left(\mathrm{m}^{2} \mathrm{a}\right)$ ile Avustralya'da iken, en yüksek $52 \mathrm{kWh} /\left(\mathrm{m}^{2} \mathrm{a}\right)$ ile Ingiltere'de görülmektedir. Metrekare başına yıllık toplam birincil enerji ihtiyacı ise en düşük 66 $\mathrm{kWh} /\left(\mathrm{m}^{2} \mathrm{a}\right)$ ile Japonya'da, en yüksek 190 $\mathrm{kWh} /\left(\mathrm{m}^{2} \mathrm{a}\right)$ ile Avusturya'da görülmektedir. Türkiye'de bulunan tek EnerPHit yapısında ise metrekare başına yıllık ısıtma enerjisi ihtiyacının 20 $\mathrm{kWh} /\left(\mathrm{m}^{2} \mathrm{a}\right)$, toplam birincil enerji ihtiyacının ise 79 $\mathrm{kWh} /\left(\mathrm{m}^{2} \mathrm{a}\right)$ olduğu görülmekte ve bu değerler ile enerji tüketiminde yapılan tasarruf bakımından ülkeler arasında iyi bir konumda yer almaktadır. Ancak Türkiye'de EnerPHit sertifikasına sahip sadece bir örnek bulunmaktadır.

\subsection{Mevcut Bir Bina İçin Uygulama}

İzmir Karşıyaka' da bulunan 8 katlı, 36 daireli bir bina, EnerPHit U-değerleri sınır değerleri uygulaması için seçilmiştir. Seçilen apartman yapısının her katında dört ayrı mesken bulunmaktadır. Her bir bağımsız meskenin kullanım alanı $82 \mathrm{~m}^{2 \prime}$ dir.
Seçilen binanın planı, önce Autocad programı ile 2 boyutlu düzenlemeler yapılarak Design Builder programında kullanılmak amacıyla hazırlanmış, ardından Design Builder programı ile modeli oluşturulmuştur.

Çizelge 8. Çalışmanın uygulaması amacıyla seçilen binaya ait bilgiler

\begin{tabular}{ll} 
Uygulama amaçlı seçilen binaya ait bilgiler ve özellikler \\
\hline Bina tipi & Apartman \\
Konum & Karşıyaka, İzmir, Türkiye \\
Yapım yılı & 2012 \\
Toplam kullanım alanı & $2952 \mathrm{~m}^{2}$ \\
Dış duvarlar & U-değeri $2,261 \mathrm{~W} / \mathrm{m}^{2} \mathrm{~K}$ \\
Çatı & U-değeri $2,149 \mathrm{~W} / \mathrm{m}^{2} \mathrm{~K}$ \\
Zemin & U-değeri $1,575 \mathrm{~W} / \mathrm{m}^{2} \mathrm{~K}$ \\
Pencereler & U-değeri $1,96 \mathrm{~W} / \mathrm{m}^{2} \mathrm{~K}$ \\
Mekanik havalandırma & - \\
Isıtma & Doğalgaz \\
Soğutma ve birincil enerji ihtiyacı & Elektrik \\
Isıtma enerjisi ihtiyacı & $51,08 \mathrm{kWh} / \mathrm{m}^{2}(\mathrm{yıllık})$ \\
Birincil enerji ihtiyacı & $234,87 \mathrm{kWh} / \mathrm{m}^{2}(\mathrm{y} ı l l ı k$ \\
\hline
\end{tabular}

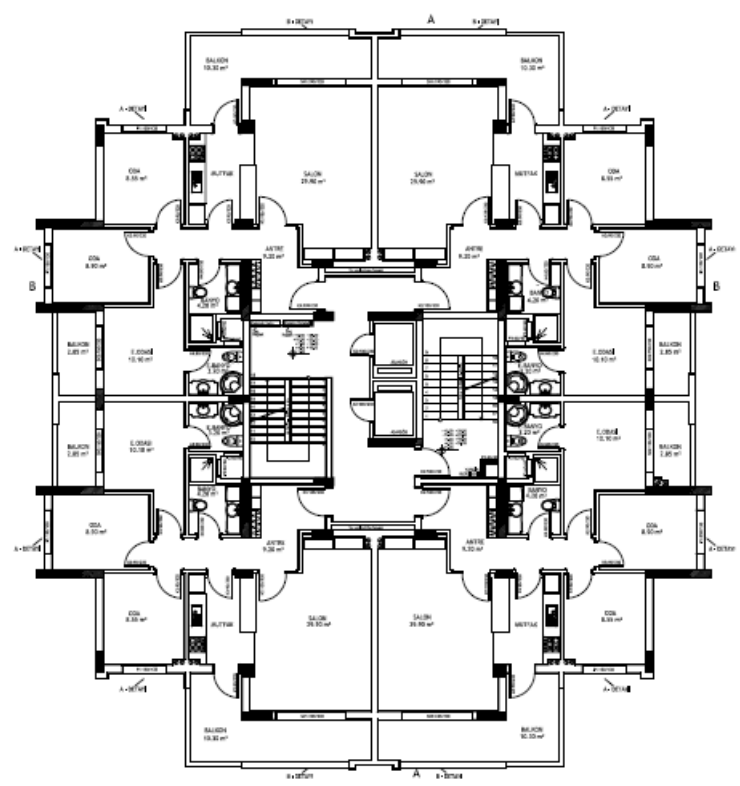

Şekil 8. Seçilen binanın kat planı 


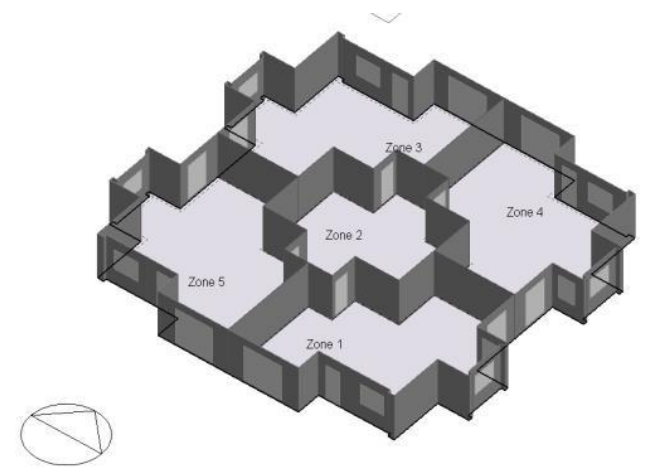

Şekil 9. Seçilen binanın Design Builder modelinde plan aksonometrisi

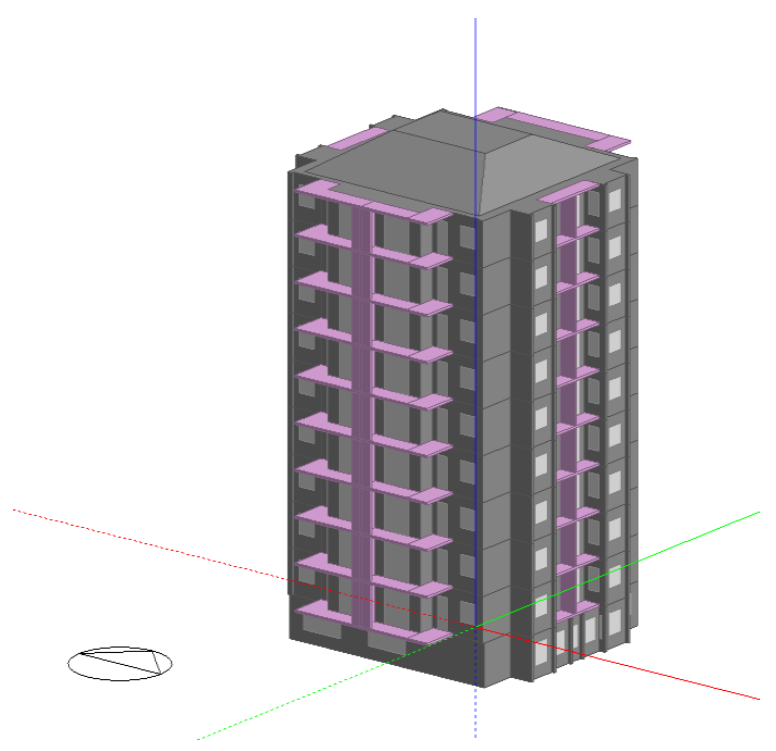

Şekil 10. Seçilen binanın Design Builder modeli

Model oluşturulduktan sonra sırasıyla aşağıdaki yöntem izlenmiştir;

-İzmir iklim verilerini yükleme,

-Modelin yapı malzemelerini atama,

-Modelde kullanıcı alışkanlıklarının girdisini oluşturma,

- Yapının 24 saat içerisindeki (hafta içi, cumartesi ve pazar günleri ayrı ayrı) aydınlatma senaryosunu oluşturma,

-Yapının 24 saat içinde doluluk senaryosunu oluşturma (hafta içi, cumartesi ve pazar günleri ayrı ayrı),

-Yapının ısıtma ve soğutma sistemlerini belirleme. Yukarıda belirtilen adımlar tamamlanarak modelin simülasyonu yapılmış ve yapının mevcut halinin ve EnerPHit U-değerleri yönteminde belirtilen sınır değerler çerçevesinde iyileştirilmiş halinin enerji tüketim değerlerine ulaşılmıştır.

\section{Bulgular}

Çalışmada kullanılan binanın mevcut ve iyileştirilmiş durumuna ait malzeme katmanları ve U-değerleri Çizelge 9'da gösterilmektedir. Yapının mevcut ve iyileştirilmiş durumu, Design Builder programı ile modellenip simülasyonu yapılmış ve enerji ihtiyacı değerlerine ulaşılmıştır. (Çizelge 10)

Çizelge 9. Yapının mevcut ve iyileştirilmiş durumuna ait malzeme katmanları

\begin{tabular}{|c|c|c|c|c|}
\hline & Dış Duvar & Çatı & Zemin & Pencere \\
\hline Mevcut yapı & $\begin{array}{l}2 \mathrm{~cm} \text {. Sıva } \\
19 \mathrm{~cm} \text {. Dolu tuğla } \\
2 \mathrm{~cm} \text {. Sıva }\end{array}$ & $\begin{array}{l}2.5 \mathrm{~cm} \text {. Kiremit } \\
0.5 \mathrm{~cm} \text {. Membran } \\
0.5 \mathrm{~cm} \text {. Ahşap levha } \\
\text { Hava boşluğu } \\
12 \mathrm{~cm} \text {. Betonarme } \\
\text { Döşeme } \\
2 \mathrm{~cm} \text {. Sıva }\end{array}$ & $\begin{array}{l}2 \mathrm{~cm} \text {. Mermer } \\
3 \mathrm{~cm} \text {. Şap } \\
50 \mathrm{~cm} \text {. Betonarme } \\
\text { döșeme } \\
0.5 \mathrm{~cm} \text {. Membran } \\
10 \mathrm{~cm} \text {. Grobeton }\end{array}$ & $\begin{array}{l}4+12+4 \text { (Hava } \\
\text { dolgulu) }\end{array}$ \\
\hline U-değeri & $2,261 \mathrm{~W} / \mathrm{m}^{2} \mathrm{~K}$ & $2,149 \mathrm{~W} / \mathrm{m}^{2} \mathrm{~K}$ & $1,575 \mathrm{~W} / \mathrm{m}^{2} \mathrm{~K}$ & $1,96 \mathrm{~W} / \mathrm{m}^{2} \mathrm{~K}$ \\
\hline $\begin{array}{l}\text { İyileştirilmiş } \\
\text { yapı }\end{array}$ & $\begin{array}{l}2 \mathrm{~cm} \text {. Siva } \\
12 \mathrm{~cm} \text {. EPS } \\
19 \mathrm{~cm} \text {. Dolu tuğla } \\
2 \mathrm{~cm} \text {. Siva }\end{array}$ & $\begin{array}{l}2.5 \mathrm{~cm} \text {. Kiremit } \\
0.5 \mathrm{~cm} \text {. Membran } \\
0.5 \mathrm{~cm} \text {. Ahşap levha } \\
\text { Hava boşluğu } \\
11 \mathrm{~cm} \text {. Cam yünü } \\
12 \mathrm{~cm} \text {. Betonarme } \\
\text { Döşeme } \\
2 \mathrm{~cm} \text {. Sıva }\end{array}$ & $\begin{array}{l}2 \mathrm{~cm} \text {. Mermer } \\
3 \mathrm{~cm} \text {. Şap } \\
8 \mathrm{~cm} \text {. XPS } \\
50 \mathrm{~cm} \text {. Betonarme } \\
\text { döşeme } \\
0.5 \mathrm{~cm} . \text { Membran } \\
10 \mathrm{~cm} \text {. Grobeton }\end{array}$ & $\begin{array}{l}\text { Isıcam } \\
4+16+4+16+4 \\
\text { (Argon) K }\end{array}$ \\
\hline U-değeri & $0,254 \mathrm{~W} / \mathrm{m}^{2} \mathrm{~K}$ & $0,287 \mathrm{~W} / \mathrm{m}^{2} \mathrm{~K}$ & $0,294 \mathrm{~W} / \mathrm{M}^{2} \mathrm{k}$ & $0,6\left(\mathrm{~W} / \mathrm{m}^{2} \mathrm{~K}\right)$ \\
\hline
\end{tabular}

Çizelge 10. Yapının mevcut ve iyileştirilmiş durumuna ait

\begin{tabular}{lcccc}
\multicolumn{5}{c}{ enerji ihtiyacl } \\
\hline & $\begin{array}{l}\text { Toplam Birincil } \\
\text { Enerji İhtiyacı } \\
\mathbf{k W h}\end{array}$ & $\begin{array}{l}\text { Toplam Isıtma } \\
\text { Enerjisi İhtiyacı } \\
\mathbf{k W h}\end{array}$ & $\begin{array}{l}\mathbf{m}^{\mathbf{2}} \text { için Birincil } \\
\text { Enerji İhtiyacı } \\
\mathbf{k W h} / \mathbf{m}^{2}\end{array}$ & $\begin{array}{l}\mathbf{m}^{2} \text { için Isıtma } \\
\mathbf{E n e r j i s i ~ I ̇ h t i y a c ı ~} \\
\mathbf{k W h} / \mathbf{m}^{2}\end{array}$ \\
\hline $\begin{array}{l}\text { Mevcut yapı } \\
\text { Iyileștirilmiş }\end{array}$ & 837166,26 & 182086,50 & 234,87 & 51,08 \\
$\begin{array}{l}\text { yapı } \\
\text { Tasarruf }\end{array}$ & 425578,83 & 66158,62 & 119,40 & 18,56 \\
\hline
\end{tabular}

Bu aşamada yapının birincil enerji ihtiyacı ve ısıtma enerjisi ihtiyacının iyileştirme öncesi ve sonrası değerleri karşılaştırılmıştır. EnerPHit sertifikası Udeğerleri kriterleri asgari düzeyde bir apartman yapısında karşılandığında elde edilen birincil enerji ihtiyacı tasarrufu \%49 ve Isıtma enerjisi ihtiyacı tasarrufu ise \%63 olmuştur. Belirtilen tasarruf miktarları; yalıtımın düzeyi, yapı tipi, iklim bölgesi, kullanıc senaryosu, opak ve saydam yüzey alanı, yapının yönlenmesi gibi parametrelere bağlı olarak değişiklik gösterebilecektir. 


\section{Tartışma ve Sonuç}

Türkiye'de Binalarda Enerji Performansı Yönetmeliği öncesinde yapılan yapıların büyük çoğunluğunun, enerjinin etkin ve verimli kullanılmadığı yapılar olduğu bilinmektedir. Mevcut yapılarda yapılacak enerji etkin iyileştirmelerin, ülke genelinde en yüksek tüketim payının binalarda olduğu düşünüldüğünde etkisinin hızlı ve büyük olacağı görülmektedir. İyileştirme EnerPHit gibi sertifika sistemleri çerçevesinde yapıldığında ise yaklaşık \%50-\%60 oranında tasarruf sağladığı, aktif sistemler ile desteklendiğinde ise \%100'e varan tasarruf sağlayabileceği öngörülebilmektedir. "Konut sektöründeki enerji tüketiminin $\% 70$ oranında azaltılması 12 milyon TEP enerji tasarruf edilmesi demektir, bu durumda enerji istatistiklerinde verilen fiyatlara göre yıllık enerji faturasında 6 milyar ABD doları tasarruf sağlanmış olmaktadır." (Dilmac ve Tırıs bt.) Avrupa Birliği tarafından yayınlanan Binalarda Enerji Performansı Direktifi doğrultusunda ülkeler kendi NZEB hedeflerini belirlerken; düşük enerji tüketimi, yaşam döngüsü sürecinde maliyet etkinlik, fosil yakıt tüketiminde ve karbon salımında önemli ölçüde azalma sağlayan yöntemlerin kullanılması ve geliştirmesini esas almışlardır. Pasif Ev ve mevcut yapılarda kullanılan versiyonu olan EnerPHit sertifika sistemi de ülkelerin çoğunun belirlediği enerji tüketimi değerlerini karşılayan bir sertifika sistemi olarak binalarda artan bir hızla kullanılmaya başlanmış ve sertifikalanmış yapı sayısında hızlı bir artış olmuştur.

Türkiye'de de Avrupa Birliği'ne uyum sürecinde; yeni yapıların enerji tüketimi açısından belirli sınır değerler çerçevesinde inşa edilmesi, mevcut yapıların kısa sürede EnerPHit sertifika sistemi doğrultusunda iyileştirilmesi, örneklerde de görüldüğü gibi enerji tüketim değerlerini büyük oranda düşürebilecektir. İncelenen örneklere ve Türkiye'deki örneğe bakıldığında, ülkemizde yaygın kullanıma sahip XPS, mineral yün, EPS gibi yalıtım malzemelerinin büyük oranda tercih edildiği, dolayısıyla ülkemizde yalıtım malzemesi temini açısından da uygulanabilirliğinin olduğu görülebilmektedir.
Türkiye'deki yapı tipinin yaklaşık \%87'sini oluşturan konutlarda, mevcut yapıların EnerPHit doğrultusunda iyileştirilmesi, bina sektörünün enerji tüketimini ve karbon salımını büyük oranda azaltacaktır. Enerjinin etkin ve verimli kullanılması ile gelecek nesillere sağlıklı bir dünya bırakmak konusunda çok büyük bir adım atılmış olurken, ülkenin enerji konusundaki dışa bağımlığı azaltıımış, dünya enerji görünümüne uyum sağlanmış, daha düşük kullanım maliyetleri ile daha konforlu bir yaşam kazanılmış olacaktır. EnerPHit sertifika sisteminin Türkiye'de mevcut yapılarda kullanımının artmasıyla birlikte,

-Binalarda enerji tüketimi büyük oranda azalacak, -Kullanım süresince enerji maliyetleri azalacak, -Enerji maliyetlerinin azalması ile birlikte; kullanıcıların tasarruf için seçtiği yöntemlerden birisinin binalarda ısıtma-soğutma olmasının önüne geçilip daha konforlu mekânlarda yaşamın devam etmesi sağlanacak,

-Gelecek nesillere sağlıklı ve yaşanabilir bir dünya bırakmak konusunda çok büyük bir adım atılmış olacak,

-Fosil yakıt tüketimi ve karbon salımı azalmış olacak, -Enerjide dışa bağımlılık azaltılmış olacaktır.

Binalarda enerjinin etkin ve verimli kullanılmasını, mevcut konfor koşullarının iyileştirilmesini, yakıt tüketiminin büyük oranda azaltılmasını sağlayan EnerPHit sertifika sisteminin, ülkemizde bilinirliğinin ve sertifikalı yapıların yaygınlaşmasının arttırılması hedeflenerek çalışmalar yapılması önerilmektedir. ilerleyen dönemlerde yapılacak çalışmalarda;

EnerPHit sertifika sisteminin ilk yatırım maliyeti, ilk yatırım maliyetinin geri dönüş süresi, yaşam döngüsünde enerji tasarrufuna katkısı gibi konular, bilimsel çalışmalar ile ortaya konmalı, faydaları ve etkinliği tartışılmalıdır. Türkiye'de binalarda enerji tüketiminin azaltılmasına yönelik uygulamaların arttırılması amacıyla kullanıcılara; seçenekler, yöntemler, ilk maliyetler ve uzun vadede elde edilecek enerji tasarrufu konularında bilgi aktarımının yapılması gerekmektedir. Bu çalışma EnerPHit sertifika sisteminin, Türkiye'deki bina sektöründeki enerji verimliliğine potansiyel katkısını 
incelemek ve uygulanabilirliğini araştırmak amacıyla ortaya konmuştur.

\section{Kaynaklar}

Aşıkoğlu, A. 2014. Sürdürülebilir konut yapılarında pasif sistemlerin kullanılan teknikler açısından irdelenmesi; İzmir ili için bir uygulama önerisi. Yüksek Lisans Tezi, Dokuz Eylül Üniversitesi Fen Bilimleri Enstitüsü, İzmir, 222.

Aşıkoğlu, A., Altın, M. 2016. Passive system techniques used in sustainable buildings. Proceedings of the 8 th International Ege Energy Symposium and Exhibition. Afyonkarahisar

Causeone, F., Pietrobon, M., Pagliano, L. and Erba, S. 2017. A high performance home in the mediterranean climate: From the design principle to actual measurements. Energy Procedia, 140, 6779.

Cotterel, J. and Dadeby, A., 2014. The Passivhaus handbook. Devon: Green Books, 44-46.

Çevre ve Şehircilik Bakanlığı,2020. https://cevresel gostergeler.csb.gov.tr/sektorlere-goretoplam-enerjituketimi-i-85800 (Erişim tarihi: 7.01.2021)

Dilmac, Ş. ve Tırıs, M., b.t.. Türkiye'de konut sektöründe enerjitasarrufu.http://www1.mmo.org.tr/resimler/d osya_ekler/d616dd38211ebb5_ek.pdf?\%20 dergi=160 (Erişim tarihi: 27.05 .2021 )

ECOFYS, 2014. Overview of Member States information on NZEBs Working version of the progress reportfinal report

European Union [EU]., 2010. Directive 2010/31/EU of the European Parliament and of the Council of 19 May 2010 on the energy performance of buildings (recast).

Eerg., b.t. The Passive-On Project. http://www.eerg.it/ passiveon.org/e/ (Erişim tarihi: 05.12.2020)

Hopfe C.J. and McLeod R.S., 2015. Passivhaus designer's manual: a technical guide to low and zero energy buildings. London: Routledge, 98-101.

Liang, X., Wang, Y., Royapoor, M., Wu, Q. and Roskilly, T., 2017. Comparison of building performance between Conventional House and Passive House in the UK. Energy Procedia. 142, 1823-1828.

OeEB by Allplan GmbH. 2013. Allplan GmbH Energy Efficiency Potential Country Report: TURKEY. Vienna,AUSTRIA.bhttps://www.oeeb.at/dam/jcr:e9c 73d64-c299-4452-b294-70491d7673f0/OeEB-Study -Energy-Efficiency-Finance-Turkey.pdf (Erişim tarihi: 05.05.2021)

Passipedia, 2018. https://passipedia.org (Erişim tarihi: $05.12 .2020)$

Schnieders, J., Eian, T.D., Filippi, M., Florez, J., Kaufmann, B., Pallantzas, S., Paulsen, M., Reyes, E., Wassouf, M. and Yeh, S.-C. 2020. Design and realisation of the Passive House concept in different climate zones. Energy Efficieny, 13, 1561-1604

Şenyurt, S. ve Altın, M. 2020. Ofis yapıları için çevreyle uyumlu yapı dış kabuğu tasarım parametrelerinin enerji tüketimine etkisini belirlemede kullanılabilecek bir yaklaşım. MEGARON, Cilt:15, 1, 55-66.

ULUSAL ENERJi VERIMLILIĞi EYLEM PLANI, 2017. https://www.resmigazete.gov.tr/eskiler/2018/01/2 0180102M1-1-1.pdf (Erişim tarihi: 03.01.2021)

Umaroğulları, F., Gedik, G. ve Mıhlayanlar, E., 2011. Periyodik rejimde yalıtımlı ve yalıtımsız betonarme duvarlarda yoğuşma denetimi: Edirne örneği. MEGARON, 6, 13-20.

Yeang, K., 2008. Eko Tasarım. Burçin Yılmaz (editör), İstanbul: YEM Yayınevi, 234-235

Yearbook Enerdata., 2020. https://yearbook.enerdata. net/total-energy/world-consumptionstatistics.html (Erişim tarihi: 05.12.2020)

Yıldız, Y., Özbalta, T. ve Arsan, Z., 2011. Farklı cam türleri ve yönlere göre pencere/duvar alanı oranının bina enerji performansına etkisi: Eğitim binası, İzmir. MEGARON,6, 30-38.

\section{internet kaynakları}

1-https://passiv.de/en/01 passivehouseinstitute/ 01 passivehouseinstitute.htm, (05.12.2020)

2-https://passivehouse.com/02 informations/01 
whatisapassivehouse/01 whatisapassivehous,

(07.06.2021)

3- https://passipedia.org/certification/enerphit,

(07.06.2021)

4-https://passivehouseinternational.org/index.ph p?page id=150, (07.06.2021)

5-https://passivehousedatabase.org/index.php?la ng=en, (07.06.2021) 